\title{
Evaluation of Operative Notes Concerning Laparoscopic Cholecystectomy: Are Standards Being Met?
}

\author{
Linda S. G. L. Wauben • Richard H. M. Goossens • \\ Johan F. Lange
}

Published online: 29 January 2010

(C) The Author(s) 2010. This article is published with open access at Springerlink.com

\begin{abstract}
Background Laparoscopic cholecystectomy (LC) is the most performed minimal invasive surgical procedure and has a relatively high complication rate. As complications are often revealed postoperatively, clear, accurate, and timely written operative notes are important in order to recall the procedure and start follow-up treatment as soon as possible. In addition, the surgeon's operative notes are important to assure surgical quality and communication with other healthcare providers. The aim of the present study was to assess compliance with the Dutch guidelines for writing operative notes for LC.

Methods Nine hospitals were asked to send 20 successive LC operative notes. All notes were compared to the Dutch guideline by two reviewers and double-checked by a third reviewer. Statistical analyses on the "not described" items were performed.

Results All hospitals participated. Most notes complied with the Dutch guideline (52-69\%); 19-30\% of items did not comply. Negative scores for all hospitals were found, mainly for lacking a description of the patient's posture (average 69\%), bandage (94\%), blood loss (98\%), name of the scrub nurse $(87 \%)$, postoperative conclusion $(65 \%)$, and postoperative instructions (78\%). Furthermore, notes from one community hospital and two teaching hospitals complied significantly less with the guidelines.
\end{abstract}

L. S. G. L. Wauben $(\bowtie) \cdot$ R. H. M. Goossens

Faculty of Industrial Design Engineering, Delft University of Technology, Landbergstraat 15, 2628 CE Delft, The Netherlands e-mail: 1.s.g.l.wauben@tudelft.nl

L. S. G. L. Wauben · J. F. Lange

Department of Surgery, Erasmus University Medical Center,

's-Gravendijkwal 230, 3015 GD Rotterdam, The Netherlands
Conclusions Operative notes do not always fully comply with the standards set forth in the guidelines published in the Netherlands. This could influence adjuvant treatment and future patient treatment, and it may make operative notes less suitable background for other purposes. Therefore operative note writing should be taught as part of surgical training, definitions should be provided, and procedure-specific guidelines should be established to improve the quality of the operative notes and their use to improve patient safety.

\section{Introduction}

Laparoscopic cholecystectomy (LC) is the most performed minimally invasive surgical procedure performed by both junior and senior physicians (approximately 15,000-19,000 are performed annually in the Netherlands) [1-3]. It is the method of choice for gallbladder removal, and in the Netherlands the Dutch Society of Surgery has adopted a guideline for performing the procedure [4] (for the English translation see Figure 3 in Wauben et al. 2008 [5]). However, the complication rate (e.g., trocar injury, injury to the common bile duct, vascular injury) is still relatively high in comparison to open cholecystectomy: the rates for bile duct injury range from 0.3 to $0.5 \%$ [1-3, 6-8]. As these complications are often revealed postoperatively, accurate operative notes are important in order to recall the procedure and start follow-up treatment (e.g., surgical intervention such as relaparotomy, percutaneous drainage, or nonsurgical intervention, such as placing a stent or the performance of percutaneous transhepatic dilatation) as soon as possible [1-3, 8-12].

Operative notes written by the surgeon are used for systematic documentation of every operation and are an essential element in safe patient care and follow-up [9-15]. 
In addition, they are useful for research, education, medicolegal cases, and quality assurance [8-21]. Although all of these issues require registration of particular items, general requirements have to be met: operative notes have to be clear, accurate, and written in a timely fashion [12, 21].

To assure surgical quality and communication with other healthcare providers (e.g., nursing staff, general practitioner, surgeon performing follow-up consultation), associations and organizations have dictated explicit standards (guidelines) concerning the time frame and content of operative notes [22-24]. All such guidelines have similar standards (Table 1), but previous research has shown that these standards are not always upheld. The time frame between surgery and operative note writing (dictation) is often unclear, and the quality of the operative notes is variable and poor $[14,15,17,18$, $20,21]$.

The aim of the present study was to assess compliance with the Dutch guideline for writing operative notes concerning laparoscopic cholecystectomy.

\section{Materials and methods}

\section{Data collection}

Nine hospitals (i.e., two academic hospitals, six teaching hospitals, and one non-teaching hospital) were contacted to participate in the study. To be included, each hospital had to collect and send 20 successive LC operative notes. The names of the hospitals, patients, and staff could be obscured for privacy reasons, but it was important to be able to see whether names had been filled out.

Data analysis

All operative notes were blinded to the reviewers for the different hospitals. All notes were compared by two reviewers to the different items of the guideline of the Dutch Society of Surgery (edition 2002) [23] and rated item by item as "described (1)," "not described (0)," or "not applicable."

To reach interrater agreement, two operative notes were fully analyzed by two different reviewers (with no medical background) and compared and discussed with a third reviewer (L.W.). No systematic differences between the three reviewers were observed. However, it was decided in consultation with a surgical expert (J.L.) to rate the items "antibiotic prophylaxis," "complication(s)," "specific medication," "drains, etc," and "histology" as "not applicable" because these were not mandatory according to
Table 1 Content and time frame described in guidelines for operative note writing [22-24]

\begin{tabular}{|c|c|c|c|}
\hline & DSS-2002 & RCS-2008 & $\mathrm{JC}-2008$ \\
\hline Procedure date & $\times$ & $x$ & \\
\hline Procedure time & & $x$ & \\
\hline Consultant name & & $x$ & \\
\hline Name patient & $\times$ & & \\
\hline Gender patient & $x$ & & \\
\hline Date of birth patient & $\times$ & & \\
\hline PID number patient & $x$ & & \\
\hline Operator & $x$ & $\times$ & $\times$ \\
\hline Assistant(s) & $x$ & $x$ & $x$ \\
\hline Anesthetist & $x$ & $x$ & $x$ \\
\hline Scrub nurse & $x$ & $x$ & $x$ \\
\hline Indication for surgery & $x$ & $x$ & \\
\hline Type of anaesthesia & $x$ & & \\
\hline Antibiotic prophylaxis & $\times$ & & \\
\hline Patient posture & $x$ & & \\
\hline Incision & $x$ & $\times$ & \\
\hline $\begin{array}{l}\text { Confirmation expected } \\
\text { general pathology }\end{array}$ & $x$ & $x$ & \\
\hline $\begin{array}{l}\text { Unexpected } \\
\text { events/complications }\end{array}$ & $x$ & $x$ & \\
\hline Extra procedure(s) & & $x$ & \\
\hline Procedure performed: & & & $x$ \\
\hline Remove gallbladder & $x$ & $x$ & \\
\hline Haemostasis & $\times$ & & \\
\hline Closure & $x$ & & \\
\hline Type of sutures/staplers & $x$ & $x$ & \\
\hline Bandage & $x$ & & \\
\hline Specific medication & $x$ & & \\
\hline Drains/catheters/probes & $x$ & & \\
\hline Histology & $x$ & & \\
\hline Blood loss & $x$ & & $x$ \\
\hline $\begin{array}{l}\text { Postoperative } \\
\text { conclusion/summary }\end{array}$ & $x$ & & $x$ \\
\hline $\begin{array}{l}\text { Postoperative } \\
\text { instructions/treatment }\end{array}$ & $x$ & $x$ & \\
\hline
\end{tabular}

DSS Dutch Society of Surgery, RCS Royal College of Surgeons England, JC Joint Commission

the LC guidelines [4]. The two reviewers then reviewed all notes independently, and then came together to discuss any uncertainties. All ratings were double-checked by the third reviewer.

Statistical analyses were performed on the "not described" ratings of the operative notes using SPSS 16.0 for Mac. The Kruskal-Wallis test was then performed, followed by exploratory Mann-Whitney $U$-tests. The Bonferroni adjustment for multiple comparisons was applied. 


\section{Results}

All nine hospitals participated in the study: two academic hospitals (A1, A2), six teaching hospitals (T1-T6), and one non-teaching hospital (C1). Teaching hospital T6 did not send the complete operative notes: patient and staff information (steps 1-3, Table 2) were deleted for privacy reasons. Hospital T5 only sent eleven operative notes.

Compliance with reporting content per hospital

Figure 1 shows that most hospitals' notes comply with the Dutch guideline (52-69\%); only $19-30 \%$ of the items in the notes did not comply. Table 2 provides the percentages (per hospital) at which the notes described specific items or at which items were not applicable.

Table 2 shows that items related to patient information were described in most notes, except for the description of the patient gender in the notes of hospitals T3 and T5. The procedure date was described in all notes.

Provision of the names of the operator, assistant(s) and anesthetist complied with the guidelines in most cases (on average in 100, 84, and $92 \%$ of cases, respectively). However, the name of the scrub nurse was given only in most notes of hospital T3.

The indication for surgery was described in all operative notes. Also, all hospitals (except C1) described the type of anesthesia in most notes. Antibiotic prophylaxis was often not applicable (average 79\%). The patient's posture was described in $50 \%$ of notes of hospitals A1 and T2. Notes from the remaining hospitals included fewer descriptions of patient posture (10-45\% of cases). Hospital C1 did not describe patient posture at all. Item 5.4 "incision" was described in most operative notes (average $95 \%$ ).

In seven hospitals most notes (55-95\%) confirmed the expected general pathology. However, the notes from hospitals T4 and T6 described the expected general pathology in only 30 and $50 \%$ of cases, respectively. On average, complications and unexpected events (e.g., bleeding, iatrogenic gallbladder perforation) occurred in $44 \%$ of cases and were documented in all hospitals' notes, including the additional procedures performed to treat the complication.

Removal of the gallbladder was described in all operative notes. On average $81 \%$ of notes described "checking for hemostasis" as part of the procedure. Step 5.8 "closure" was described in all hospitals notes, except for two notes $(10 \%)$ from hospital T6. "Types of suture" was described in most notes (85-100\% of cases), except for the notes of hospital $\mathrm{C} 1$, which described the type of suture in only $45 \%$ of cases. "Type of bandage" was described in very few notes (average 6\%).
Step 6.1 "administering specific medication" and step 6.2 "placing of drains or removing catheters" were often noted as not applicable (average 79 and $87 \%$, respectively). Sending the retrieved gallbladder for histology was described in $10-65 \%$ of cases. In the remaining cases this step was rated "applicable." The amount of blood loss was described in one note each from hospitals A1, T5, and T6.

None of the hospitals' notes described both the postoperative conclusion and the postoperative instructions. Notes from hospitals A1, T2, T3, and T6 mostly included postoperative conclusions (50-90\%), whereas the notes from hospitals $\mathrm{T} 1$ and $\mathrm{T} 4$ stated the postoperative instructions (75 and 100\%, respectively). The notes from hospitals A2 and T5 included neither of these items.

\section{Differences between hospitals for "not described"} items

The average percentages of items "not described" per operative note were compared by hospital (Fig. 2). Hospital T6 was excluded from this comparison because of the large amount of missing data.

Figure 2 shows that hospitals $\mathrm{C} 1, \mathrm{~T} 3$, and T5 have the highest mean scores in items "not described" in their operative notes. Mann Whitney $U$-tests (with the Bonferroni correction; significance $p<0.0018$ ) showed significant differences between hospital $\mathrm{C} 1$ and all other hospitals except hospitals T3 and T5 (Table 3). No significant differences were observed between hospitals T3 and T5. Hospitals T3 and T5 show significant differences between hospitals A1, A2, T1, and T4. Furthermore, no significant differences were observed between hospitals A1, A2, and T1. Hospital T2 only showed significant differences with hospitals $\mathrm{C} 1$ and $\mathrm{T} 4$.

\section{Discussion}

Accurate and complete operative notes are considered a critical element of quality assurance in surgery. However, operative notes are often incomplete, impeding the patient's postoperative management. Standards and guidelines aim to improve operative note writing. Although a guideline is not a law, it still has to be observed as good practice. If a surgeon deviates from the guideline, a reason has to be provided.

Although the present study shows an average overall compliance of $62 \%$, in $24 \%$ of all LCs recorded in the participating hospitals, the operative notes did not comply with the Dutch guideline (in $14 \%$ of cases items were designated "not applicable"). Negative scores for all hospitals were mainly attributable to the lack of a description of patient posture (average 69\%), type of bandage (94\%), 
Table 2 Percentages of items on the Dutch guideline described or not applicable (n/a), by hospital

\begin{tabular}{|c|c|c|c|c|c|c|c|c|c|c|c|c|}
\hline Step no. & Items & A1 & $\mathrm{A} 2$ & $\mathrm{C} 1$ & $\mathrm{~T} 1$ & $\mathrm{~T} 2$ & T3 & $\mathrm{T} 4$ & T5 & T6 & $\begin{array}{l}\text { Total average } \\
\text { per item }\end{array}$ & $\begin{array}{l}\text { Total average } \\
\text { per category }\end{array}$ \\
\hline $1.1 \mathrm{a}$ & Name patient & 100 & 100 & 100 & 100 & 100 & 100 & 100 & 100 & $\mathrm{md}$ & 100 & 94 \\
\hline $1.1 \mathrm{~b}$ & Gender patient & 100 & 100 & 100 & 100 & 100 & 0 & 100 & 0 & md & 75 & \\
\hline 1.2 & Date of birth patient & 100 & 100 & 100 & 100 & 100 & 100 & 100 & 100 & md & 100 & \\
\hline 1.3 & PID number & 100 & 100 & 100 & 100 & 100 & 100 & 100 & 100 & md & 100 & \\
\hline 2. & Procedure date & 100 & 100 & 100 & 100 & 100 & 100 & 100 & 100 & $\mathrm{md}$ & 100 & 100 \\
\hline 3.1 & Operator & 100 & 100 & 100 & 100 & 100 & 100 & 100 & 100 & $\mathrm{md}$ & 100 & 72 \\
\hline 3.2 & Assistant(s) & 85 & 100 & 25 & 85 & 100 & 80 & 100 & 100 & md & 84 & \\
\hline 3.3 & Anesthetist & 100 & 95 & 85 & 100 & 55 & 100 & 100 & 100 & md & 92 & \\
\hline 3.4 & Scrub nurse & 0 & 0 & 5 & 0 & 0 & 80 & 0 & 18 & md & 13 & \\
\hline 4 & Indication for surgery & 100 & 100 & 100 & 100 & 100 & 100 & 100 & 100 & 100 & 100 & 100 \\
\hline 5.1 & Type of anesthesia & 100 & 100 & 35 & 80 & 100 & 85 & 100 & 91 & 65 & 84 & 68 \\
\hline \multirow[t]{3}{*}{5.2} & Antibiotic prophylaxis & 25 & & 10 & & & 25 & 25 & & 10 & 11 & \\
\hline & & 75 & 95 & 70 & 100 & 95 & 15 & 75 & 100 & 90 & 79 & \\
\hline & & $\mathrm{n} / \mathrm{a}$ & $\mathrm{n} / \mathrm{a}$ & $\mathrm{n} / \mathrm{a}$ & $\mathrm{n} / \mathrm{a}$ & $\mathrm{n} / \mathrm{a}$ & $\mathrm{n} / \mathrm{a}$ & $\mathrm{n} / \mathrm{a}$ & $\mathrm{n} / \mathrm{a}$ & $\mathrm{n} / \mathrm{a}$ & $\mathrm{n} / \mathrm{a}$ & \\
\hline 5.3 & Patient posture & 50 & 15 & 0 & 40 & 50 & 30 & 10 & 45 & 40 & 31 & \\
\hline 5.4 & Incision & 85 & 100 & 100 & 90 & 100 & 85 & 100 & 91 & 100 & 95 & \\
\hline $5.5 \mathrm{a}$ & Confirmation expected general pathology & 70 & 80 & 95 & 95 & 85 & 60 & 30 & 55 & 50 & 69 & \\
\hline \multirow[t]{3}{*}{$5.5 b$} & Unexpected events/complications & 60 & 45 & 25 & 55 & 40 & 55 & 65 & & 50 & 44 & \\
\hline & & 40 & 55 & 75 & 45 & 60 & 45 & 35 & 100 & 50 & 56 & \\
\hline & & $\mathrm{n} / \mathrm{a}$ & $\mathrm{n} / \mathrm{a}$ & $\mathrm{n} / \mathrm{a}$ & $\mathrm{n} / \mathrm{a}$ & $\mathrm{n} / \mathrm{a}$ & $\mathrm{n} / \mathrm{a}$ & $\mathrm{n} / \mathrm{a}$ & $\mathrm{n} / \mathrm{a}$ & $\mathrm{n} / \mathrm{a}$ & $\mathrm{n} / \mathrm{a}$ & \\
\hline 5.6 & Remove gallbladder & 100 & 100 & 100 & 100 & 100 & 100 & 100 & 100 & 100 & 100 & \\
\hline 5.7 & Hemostasis & 75 & 75 & 100 & 95 & 90 & 65 & 100 & 73 & 55 & 81 & \\
\hline 5.8 & Closure & 100 & 100 & 100 & 100 & 100 & 100 & 100 & 100 & 90 & 99 & \\
\hline 5.9 & Type of sutures/staples & 100 & 100 & 45 & 95 & 100 & 85 & 85 & 100 & 90 & 89 & \\
\hline 5.10 & Bandage & 5 & 30 & 0 & 0 & 10 & 10 & 0 & 0 & 0 & 6 & \\
\hline \multirow[t]{3}{*}{6.1} & Specific medication & 20 & 20 & 25 & 20 & 60 & 5 & & & 40 & 21 & $\mathrm{x}$ \\
\hline & & 80 & 80 & 75 & 80 & 40 & 95 & 100 & 100 & 60 & 79 & \\
\hline & & $\mathrm{n} / \mathrm{a}$ & $\mathrm{n} / \mathrm{a}$ & $\mathrm{n} / \mathrm{a}$ & $\mathrm{n} / \mathrm{a}$ & $\mathrm{n} / \mathrm{a}$ & $\mathrm{n} / \mathrm{a}$ & $\mathrm{n} / \mathrm{a}$ & $\mathrm{n} / \mathrm{a}$ & $\mathrm{n} / \mathrm{a}$ & $\mathrm{n} / \mathrm{a}$ & \\
\hline \multirow[t]{3}{*}{6.2} & Drains/catheters/probes & 10 & & 30 & 15 & 15 & 25 & 10 & & 10 & 16 & \\
\hline & & 90 & 100 & 70 & 85 & 85 & 75 & 90 & 100 & 90 & 87 & \\
\hline & & $\mathrm{n} / \mathrm{a}$ & $\mathrm{n} / \mathrm{a}$ & $\mathrm{n} / \mathrm{a}$ & $\mathrm{n} / \mathrm{a}$ & $\mathrm{n} / \mathrm{a}$ & $\mathrm{n} / \mathrm{a}$ & $\mathrm{n} / \mathrm{a}$ & $\mathrm{n} / \mathrm{a}$ & $\mathrm{n} / \mathrm{a}$ & $\mathrm{n} / \mathrm{a}$ & \\
\hline \multirow[t]{3}{*}{6.3} & Histology & 15 & 65 & & 10 & 60 & 35 & 35 & & 45 & 29 & \\
\hline & & 85 & 35 & 100 & 90 & 40 & 65 & 65 & 100 & 55 & 71 & \\
\hline & & $\mathrm{n} / \mathrm{a}$ & $\mathrm{n} / \mathrm{a}$ & $\mathrm{n} / \mathrm{a}$ & $\mathrm{n} / \mathrm{a}$ & $\mathrm{n} / \mathrm{a}$ & $\mathrm{n} / \mathrm{a}$ & $\mathrm{n} / \mathrm{a}$ & $\mathrm{n} / \mathrm{a}$ & $\mathrm{n} / \mathrm{a}$ & $\mathrm{n} / \mathrm{a}$ & \\
\hline 6.4 & Blood loss & 5 & 0 & 0 & 0 & 0 & 0 & 0 & 9 & 5 & 2 & 2 \\
\hline 7.1 & Postoperative conclusion/summary & 65 & 0 & 10 & 10 & 90 & 50 & 10 & 0 & 80 & 35 & 32 \\
\hline 7.2 & Postoperative instructions/treatment & 10 & 0 & 0 & 75 & 0 & 5 & 100 & 0 & 5 & 22 & \\
\hline
\end{tabular}

$m d$ missing data, $n / a$ not applicable

${ }^{\text {a }}$ Items n/a excluded

amount of blood loss (98\%), name of scrub nurse (87\%), postoperative conclusions $(65 \%)$, and postoperative instructions (78\%). Furthermore, the notes from hospitals C1, T3, and T5 complied significantly less with the guidelines when compared to most other hospitals' operative notes. For example, hospitals T3 and T5 did not describe the patient's gender.
Although some items to be included in the operative notes may seem to be logical and consistent components of all procedures, describing these items in every operative note minimizes the chance of overlooking them when they influence outcome (e.g., patient posture in relation to postoperative neuromuscular complications). Furthermore, 
Fig. 1 Compliance with Dutch guideline for writing operative notes per hospital: percentages of items "described," "not described," or "not applicable."

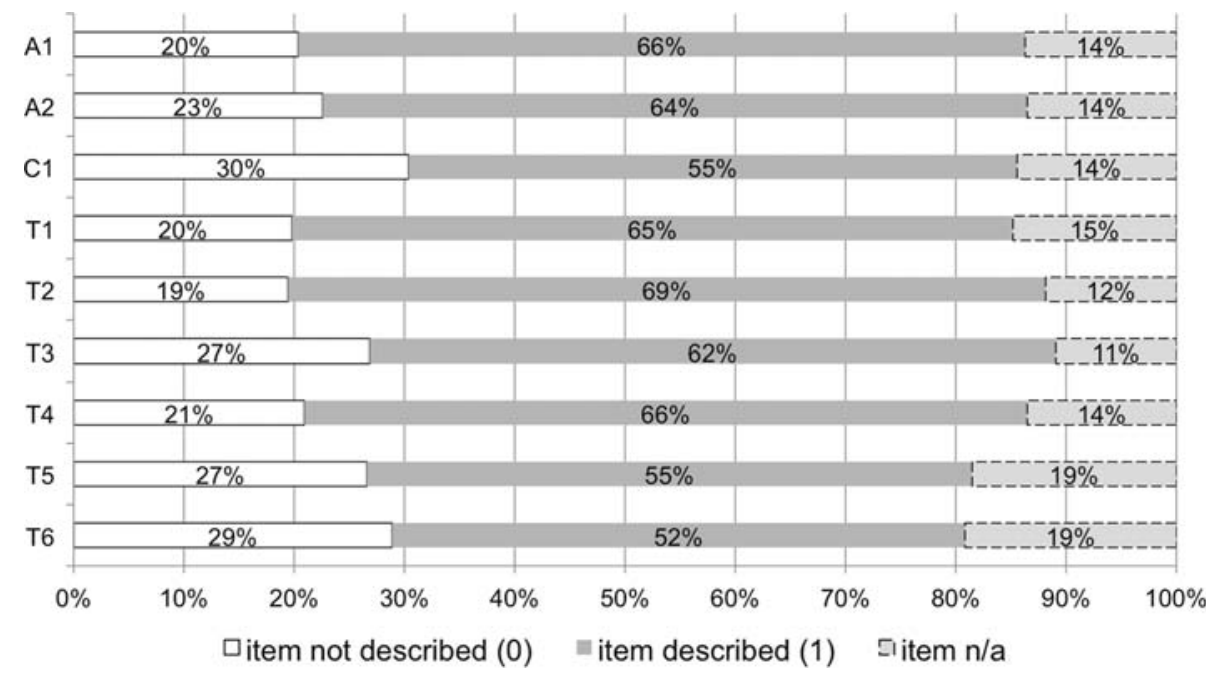

present study is relatively high (78\% of cases) when compared to other studies (entailing different surgical procedures), which show average rates of $0-42 \%$ [9-11, 13, 14, 17, 20, 25].

Although the direct effect of failure to adhere to the guideline and of incomplete and inaccurate operative notes has not yet been studied, describing items 1-4 in Table 2 is vital for quality assurance. In addition, including the subsequent items (5-7) in the operative note has a direct effect on the patient's postoperative management; therefore, not describing these items increases the safety risk. One of the complications of LC with a high socioeconomic impact is bile duct injury (BDI) $[1,3,8]$. De Reuver et al. showed that BDI was mostly $(61 \%)$ diagnosed before patient discharge (usually within the first postoperative $24 \mathrm{~h} \mathrm{[3])} \mathrm{[1].}$ However, in $34 \%$ of cases BDI was diagnosed after discharge, with a mean time interval between LC and BDI diagnosis of 4 weeks. Other studies have shown similar results: the majority of BDIs were not recognized during initial surgery $[3,8]$. Managing the complications caused by BDI (and other complications as well-e.g., bile leakage, stone spill) requires early recognition in order to reduce patient morbidity and improve the treatment outcome $[1,2,6,8]$. Other complications, such as abdominal abscess, fistula formation, cystic duct stump leakage, dislocation of clips, bile duct stricture, and trocar site bleeding, might arise months or years after operation [2, 3, 6, 7]. When assessing the surgery retrospectively, the surgeon then has to rely on the operative notes, and this presents problems if the notes are not accurate and complete [6].

The current guideline for operative note writing is applicable to all types of surgical procedures, and so they include only general requirements for describing the intraoperative findings and actions. Although the present study shows that most intraoperative findings and procedures are described according to the guideline, it is lack of postoperative instructions in the notes from the 
Table 3 Significant differences between hospitals for the "not described" items from the Dutch guideline (Mann-Whitney $U$-test: $p$ values have been adjusted for multiple comparisons using the Bonferroni method)

\begin{tabular}{|c|c|c|c|c|c|c|c|c|}
\hline \multicolumn{9}{|c|}{$p$ Value } \\
\hline & A1 & $\mathrm{A} 2$ & $\mathrm{C} 1$ & $\mathrm{~T} 1$ & $\mathrm{~T} 2$ & $\mathrm{~T} 3$ & $\mathrm{~T} 4$ & $\mathrm{~T} 5$ \\
\hline A1 & - & ns & $<0.001$ & ns & ns & $<0.001$ & ns & $<0.001$ \\
\hline A2 & ns & - & $<0.001$ & ns & ns & $<0.001$ & ns & $<0.001$ \\
\hline $\mathrm{C} 1$ & $<0.001$ & $<0.001$ & - & $<0.001$ & $<0.001$ & ns & $<0.001$ & ns \\
\hline $\mathrm{T} 1$ & $\mathrm{~ns}$ & ns & $<0.001$ & - & ns & $<0.001$ & ns & $<0.001$ \\
\hline $\mathrm{T} 2$ & ns & $\mathrm{ns}$ & $<0.001$ & ns & - & ns & $<0.001$ & ns \\
\hline $\mathrm{T} 3$ & $<0.001$ & $<0.001$ & $\mathrm{~ns}$ & $<0.001$ & ns & - & $<0.001$ & ns \\
\hline $\mathrm{T} 4$ & ns & $\mathrm{ns}$ & $<0.001$ & $\mathrm{~ns}$ & $<0.001$ & $<0.001$ & - & $<0.001$ \\
\hline $\mathrm{T} 5$ & $<0.001$ & $<0.001$ & $\mathrm{~ns}$ & $<0.001$ & $\mathrm{~ns}$ & ns & $<0.001$ & - \\
\hline
\end{tabular}

$n s$ not significant

recommended that more procedure-specific guidelines be developed. Ideally, the operative notes would consist of a general section and a procedure-specific section to allow a step-by-step operative description [16].

In the case of operative notes describing LC, the procedure-specific section should be linked to the procedural guideline provided by such (international) societies as the European Association of Endoscopic Surgery and the Society of American Gastrointestinal and Endoscopic Surgeons [26, 27]. The Dutch LC procedure guideline describes six key steps: (1) introduction of trocars under vision, (2) condition of gallbladder, (3) establishing critical view of safety (CVS), (4) placing of clips, (5) hemostasis of liver bed, and (6) removal of trocars under vision [4]. Steps 2 and 5 are already included in the general operative note's guideline. Adding the description of steps 1, 3, 4, and 6 provides a better basis for postoperative care, as all of these steps may lead to complications $[2,6,7]$.

The present study showed that complications were described in $44 \%$ of cases and, although not required by the Dutch guideline, actions to treat these complications were described in all these notes. However, it can only be assumed that in the remaining procedures no complications occurred. Therefore, if items are not applicable for a specific procedure (e.g., gallbladder perforation, assistance of scrub nurse, drains, specific medication, complications), these should be mentioned as well, proving that the notes are complete and that no items were forgotten [9].

Here we have considered the content of the operative notes, but the time frame for writing the notes and making them available is important as well (this study did not include this aspect). The Dutch guideline recommends that the operative notes are "dictated, made available, and added to the medical record as soon as possible" [23]. Other countries' guidelines require the notes to be "dictated immediately after an operative or high-risk procedure, or if this is not possible, an operative process note should be added" [22, 24]. The Joint Commission defines immediately as: "upon completion of surgery, before the patient is transferred to the next level of care" [24]. Adding a specific time frame for writing the operative notes to the Dutch guideline (e.g., within $24 \mathrm{~h}$ of the procedure) is advisable.

Although authorship of the operative notes is not studied here, it is expected that in teaching and academic hospitals most LCs are performed by residents, who then also write the operative note. A lack of formal education on operative note writing might account for the large gaps in reporting noted in the present study ( $24 \%$ of items in the guideline were not described). At present only $10-18 \%$ of institutions globally offer operative note writing as part of their residency program [10, 14, 15, 18, 19, 28], and most senior physicians have never received such training. Rogers et al. showed that residents were more likely to include accurate information about the suture used for closure, the dressing used, or the postoperative instructions than the specialists [20].

The present study did not focus on studying whether the data provided represented actual events that occurred during the operation (e.g., prophylactic administration of antibiotics). We believe that the results can be interpreted as a minimum level of deviation from the Dutch guideline. In addition, we have designed a follow-up study to establish whether the physician's position, surgeon or resident, influences the completeness and accuracy of the operative notes. For the future, the direct effects of failure to adhere to the guidelines need to be studied as well.

To improve the quality of the operative notes and the use of that information to improve patient safety, operative note writing should be taught to physicians in training as well as senior staff who never received such training; definitions should be provided, and procedure-specific guidelines should be introduced [10, 15, 19]. Implementation of processing the operative notes as a final, cross- 
checked part of the operation itself might improve reliability. Although not yet fully validated, there is a trend toward the application of information technology and services for operative notes. Systems like video registration of procedures, electronic aide-memoirs, surgical templates, and electronic reminders, will improve the accuracy and completeness of the operative notes [9-11, 13, 14, 16-21, 25].

Open Access This article is distributed under the terms of the Creative Commons Attribution Noncommercial License which permits any noncommercial use, distribution, and reproduction in any medium, provided the original author(s) and source are credited.

\section{References}

1. De Reuver PR, Rauws EA, Bruno MJ et al (2007) Survival in bile duct injury patients after laparoscopic cholecystectomy: a multidisciplinary approach of gastroenterologists, radiologists, and surgeons. Surgery 142:1-9

2. Shaikh IA, Thomas H, Joga K et al (2009) Post-cholecystectomy cystic duct stump leak: a preventable morbidity. J Dig Dis 10:207-212

3. Lillemoe KD (2006) Evaluation of suspected bile duct injuries. Surg Endosc 20:1638-1643

4. Dutch Society of Surgery (2006) Guideline laparoscopic cholecystectomy (in Dutch) in Report Minimal Invasive Surgery. Available at http://nvvh.artsennet.nl/web/file?uuid=032dba64caa5-4426-9899-97ae39a5d156\&owner=3cd7936f-81b6-41119cee-77f382fb350a. Accessed Jan 2010 [in Dutch]

5. Wauben LS, Goossens RH, van Eijk DJ et al (2008) Evaluation of protocol uniformity concerning laparoscopic cholecystectomy in the Netherlands. World J Surg 32:613-620

6. Zehetner J, Shamiyeh A, Wayand W (2007) Lost gallstones in laparoscopic cholecystectomy: all possible complications. Am J Surg 193:73-78

7. Khalid M, Rashid M (2009) Gallstone abscess: a delayed complication of spilled gallstone after laparoscopic cholecystectomy. Emerg Radiol 16:227-229

8. Roy PG, Soonawalla ZF, Grant HW (2009) Medicolegal costs of bile duct injuries incurred during laparoscopic cholecystectomy. HPB (Oxford) 11:130-134

9. Rogers BA Operation notes: an audit of the Royal College of Surgeons of Edinburgh surgical knowledge and skills web site. Available at http://www.edu.rcsed.ac.uk/lectures/lt39.htm. Accessed Aug 2008

10. Jawaid M, Askari R, Qureshi MA et al (2008) Quality of operative notes. J Postgrad Med Inst 22:274-276
11. Al Hussainy $\mathrm{H}$, Ali F, Jones $\mathrm{S}$ et al (2004) Improving the standard of operation notes in orthopaedic and trauma surgery: the value of a proforma. Injury 35:1102-1106

12. Vergis A, Gillman L, Minor S et al (2008) Structured assessment format for evaluating operative reports in general surgery. Am J Surg 195:24-29

13. Din R, Jena D, Muddu BN (2001) The use of an aide-memoire to improve the quality of operation notes in an orthopaedic unit. Ann R Coll Surg Engl 83:319-320

14. Harvey A, Zhang H, Nixon J et al (2007) Comparison of data extraction from standardized versus traditional narrative operative reports for database-related research and quality control. Surgery 141:708-714

15. Eichholz AC, Van Voorhis BJ, Sorosky JI et al (2004) Operative note dictation: should it be taught routinely in residency programs? Obstet Gynecol 103:342-346

16. Morgan D, Fisher N, Ahmad A et al (2009) Improving operation notes to meet British Orthopaedic Association guidelines. Ann R Coll Surg Engl 91:217-219

17. Lefter LP, Walker SR, Dewhurst F et al (2008) An audit of operative notes: facts and ways to improve. ANZ J Surg 78:800-802

18. Borchert D, Harshen R, Kemps M et al (2006) Operative notes teaching: re-discovery of an effective teaching tool in surgical training. Internet J Surg 8:1-11

19. Menzin AW, Spitzer M (2003) Teaching operative dictation. A survey of obstetrics/gynecology residency program directors. J Reprod Med 48:850-852

20. Rogers A, Bunting M, Atherstone A (2008) The quality of operative notes at a general surgery unit. South Afr Med J 98:726-728

21. Cohen MM, Ammon AA (1998) A solution to the problem of undictated operative reports by residents. Am J Surg 176:475-480

22. Royal College of Surgeons of England (2008) Good surgical practice. Available at http://www.rcseng.ac.uk/publications/ docs/good-surgical-practice-1. Accessed Jan 2010

23. Dutch Society of Surgery (2002) Guideline operative notes [Richtlijn operatieverslag]. Available at http://nvvh.artsennet.nl/ Artikel/Bestaande-richtlijnen-1.htm. Accessed Jan 2010

24. The Joint Commission (2008) Operative Reports. Available at http://www.jointcommission.org/AccreditationPrograms/OfficeBasedSurgery/Standards/09_FAQs/IM/Operative_Reports.htm. Accessed Jan 2010

25. Shayah A, Agada FO, Gunasekaran S et al (2007) The quality of operative note taking: an audit using the Royal College of Surgeons Guidelines as the gold standard. Int J Clin Prac 61:677-679

26. Kuwada T (2005) Highlights of the Society of American Gastrointestinal and Endoscopic Surgeons 2005 Annual Meeting, 1316 April 2005, Ft. Lauderdale, Florida. Available at http://www. medscape.com/viewarticle/506432. Accessed Jan 2010

27. Neugebauer EAM, Sauerland S, Fingerhut A et al (2006) In EAES guidelines for endoscopic surgery. Springer, Berlin

28. Moore RA (2000) The dictated operative note: important but is it being taught? J Am Coll Surg 190:639-640 